\title{
Long-term effects on cancer survivors' quality of life of physical training versus physical training combined with cognitive-behavioral therapy: results from a randomized trial
}

\author{
Anne M. May • Irene Korstjens • Ellen van Weert • \\ Bart van den Borne • \\ Josette E. H. M. Hoekstra-Weebers • \\ Cees P. van der Schans • Ilse Mesters • Jan Passchier • \\ Diederick E. Grobbee • Wynand J. G. Ros
}

Received: 22 May 2008 / Accepted: 1 October 2008 / Published online: 25 October 2008

(C) Springer-Verlag 2008

\begin{abstract}
Background We compared the effect of a 12-week groupbased multidisciplinary self-management rehabilitation program, combining physical training (twice weekly) and cognitive-behavioral therapy (once weekly) with the effect of 12-week group-based physical training (twice weekly) on cancer survivors' quality of life over a 1-year period. Materials and methods One hundred forty-seven survivors $[48.8 \pm 10.9$ years $($ mean $\pm \mathrm{SD}$ ), all cancer types, medical treatment $\geq 3$ months ago] were randomly assigned to either physical training (PT, $n=71$ ) or to physical training plus cognitive-behavioral therapy (PT $+\mathrm{CBT}, n=76$ ). Quality of life and physical activity levels were measured before and immediately after the intervention and at 3- and 9-month post-intervention using the European Organization for
\end{abstract}

A. M. May $(\varangle) \cdot$ D. E. Grobbee $\cdot$ W. J. G. Ros Julius Center for Health Sciences and Primary Care, University Medical Centre Utrecht,

P.O. Box 85500, 3508 GA Utrecht, The Netherlands

e-mail: a.m.may@umcutrecht.nl

A. M. May $\cdot$ J. Passchier

Department of Medical Psychology and Psychotherapy,

Erasmus Medical Center Rotterdam,

P.O. Box 1738, 3000 DR Rotterdam, The Netherlands

I. Korstjens $\cdot$ B. van den Borne $\cdot$ I. Mesters

Department of Health Education and Promotion,

School for Public Health and Primary Care (Caphri),

Maastricht University,

P.O. Box 616, 6200 MD Maastricht, The Netherlands
Research and Treatment of Cancer Quality of Life Questionnaire C30 questionnaire and the Physical Activity Scale for the Elderly, respectively.

Results Multilevel linear mixed-effects models revealed no differential pattern in change of quality of life and physical activity between PT and PT + CBT. In both PT and PT+ CBT, quality of life and physical activity were significantly and clinically relevantly improved immediately following the intervention and also at 3- and 9-month post-intervention compared to pre-intervention $(p<0.001)$.

Conclusion Self-management physical training had substantial and durable positive effects on cancer survivors' quality of life. Participants maintained physical activity levels once the program was completed. Combining physical training with our cognitive-behavioral intervention

E. van Weert - J. E. H. M. Hoekstra-Weebers •

C. P. van der Schans

Comprehensive Cancer Centre North-East Netherlands,

P. O. Box 330, 9700 AH Groningen, The Netherlands

E. van Weert

Centre for Rehabilitation, University Medical Centre Groningen,

University of Groningen,

P.O. Box 30.001, 9700 RB Groningen, The Netherlands

J. E. H. M. Hoekstra-Weebers

Wenckebach Institute, University Medical Centre Groningen,

University of Groningen,

P.O. Box 30.001, 9700 RB Groningen, The Netherlands

C. P. van der Schans

University for Professional Education,

P.O. Box 30030, 9700 RM Groningen, The Netherlands 
did not add to these beneficial effects of physical training neither in the short-term nor in the long-term. Physical training should be implemented within the framework of standard care for cancer survivors.

Keywords Cancer - Survivors · Quality of life - Exercise · Cognitive-behavioral therapy

\section{Introduction}

Cancer survivors often experience serious physical and psychosocial complaints caused by the disease and consequent treatment that may persist for many years [5]. Cancer patients' quality of life declines most soon after diagnosis, attenuates with the time since diagnosis, but remains at a lower level in the long-term [21,33]. Quality of life is a multidimensional construct including physical and psychosocial dimensions [1]. Studies on the effect of physical training in cancer survivors suggest that physical training is primarily associated with improved physical and functional aspects of quality of life, rather than the social and emotional domains [7, 8, 14]. A recent meta-analysis reported that cognitive-behavioral therapy had positive effects on mental health of cancer survivors [26]. Hence, combining physical training with cognitive-behavioral therapy might lead to even greater improvements in quality of life by benefiting both physical and psychosocial functioning.

We therefore developed a rehabilitation program that consisted of physical training and cognitive-behavioral therapy. Both components integrated principles of selfmanagement [9] to support cancer survivors in managing physical, psychological, and social problems. The physical training programmed focused on enhancing self-management in physical exercise and sports, while in cognitivebehavioral therapy, emphasis was put on providing structural interactive psycho-education and training in self-management skills. We investigated the effects of that program on quality of life.

We recently showed significant and clinically relevant improvements in cancer survivors' quality of life directly following our rehabilitation program compared to waitinglist control [16, 17]. Compared to no intervention, participants showed significant and clinically relevant improvements in global quality of life, role limitations due to physical problems, in physical functioning, vitality, and health change. Our physical training program complemented with cognitive-behavioral therapy did not result in greater positive effects than physical training alone on quality of life and physical fitness at the short-term (i.e., from baseline to post-intervention) [16-18]. However, longterm effects may be different. It may be that physical training has immediate effects on quality of life. Cognitivebehavioral therapy that confronts patients with personal worries and possibly increasing distress $[13,28]$ might have long-term benefits $[2,25,29]$. Hence, the long-term effects of physical training combined with cognitive-behavioral therapy on quality of life may be greater compared to the effects of physical training alone.

The aim of the present study was to compare the longterm effects (i.e., 9-month post-intervention) on quality of life of a 12-week self-management physical training intervention (PT), consisting of aerobic and resistance exercise, and group sports, with the effects of the same physical training intervention combined with cognitive-behavioral therapy $(\mathrm{PT}+\mathrm{CBT})$.

\section{Materials and methods}

A prospective, randomized multicenter trial was conducted from February 2004 through January 2007. Four Dutch centers experienced in oncological rehabilitation participated in the trial, i.e., one rehabilitation center and the rehabilitation units of two university medical centers and of one general hospital. Patient inclusion criteria were the following: age $\geq 18$ years; last curative cancer treatment completed at least 3 months before study entry; and estimated life expectancy of at least 1 year. Referral by a medical specialist or a general practitioner was needed who judged fulfillment of at least three of the following criteria to ascertain the need for rehabilitation, i.e., physical complaints, reduced physical capacity, psychological problems, increased levels of fatigue, sleep disturbances, and problems in coping with reduced physical and psychosocial functioning. Patients with cognitive disturbances, serious psychopathology, or emotional instability that might impede participation or patients needing intensive medical treatment were excluded. The medical ethics committee of the University Medical Center Utrecht and the local research ethics committees approved the study.

\section{Recruitment and allocation}

Cancer survivors were informed about the study by various methods, including leaflets handed out by oncologists and general practitioners, information in the local newspapers, and through the internet. After written consent, eligible subjects were scheduled for baseline measurements and randomized to $\mathrm{PT}$ or $\mathrm{PT}+\mathrm{CBT}$. By design, $\mathrm{PT}$ and $\mathrm{PT}+$ CBT were balanced in each center. Randomization at group level was applied; in each center, consecutive groups of eight to 12 eligible subjects were assigned to the randomly determined treatment to ascertain adequate numbers of participants in each group. Prior to enrolment of partic- 
ipants in the study, an independent researcher randomly determined the sequence of interventions at each center using a randomization list. Until the first session, participants were blinded to the rehabilitation group they were allocated to. Since PT + CBT and PT were open-label treatments, participants and therapists could not be blinded once the intervention started. Figure 1 shows the flow of participants through the trial.

\section{Intervention}

The present intervention has been described in detail elsewhere [18, 35].

Both components, PT and CBT, were based on principles of self-management [9], i.e., goal selection, information collection, information processing and evaluation, decision making, action, and self-reaction. The intervention took place in groups of eight to 12 cancer survivors. PT was supervised by two physical therapists and CBT by a psychologist and a social worker. All therapists involved were trained to apply the standardized intervention protocol. They were experienced in their profession and in the field of cancer rehabilitation.

Physical training Physical training (twice weekly, $2 \mathrm{~h}$ per session) consisted of a personalized exercise program based on baseline exhaustive exercise testing. Each session consisted of individual exercise [aerobic bicycle training (30 $\mathrm{min})$ and muscle strength training $(30 \mathrm{~min})]$ followed by group sports $(60 \mathrm{~min})$. During the training, the participants used heart rate monitors, the Borg Scale for dyspnea and fatigue [6], and training logs to monitor and evaluate their performance and received feedback, information, and support from their therapists in regulating their performance.

Aerobic bicycle training Intensity was determined using the Karvonen formula [15] that uses the peak heart rate $\left(\mathrm{HR}_{\text {peak }}\right)$ obtained from baseline exhaustive exercise testing and the heart rate at rest $\left(\mathrm{HR}_{\text {rest }}\right)$ to calculate the training $\mathrm{HR}\left(\mathrm{HR}_{\mathrm{tr}}\right)$. Exercise training was performed at a $\mathrm{HR}_{\mathrm{tr}}$ of $\left[\mathrm{HR}_{\text {rest }}+40 \%\right.$ to $50 \%$ of $\left.\left(\mathrm{HR}_{\text {peak }}-\mathrm{HR}_{\text {rest }}\right)\right]$ during the first 4 weeks and was gradually increased to $\left[\mathrm{HR}_{\text {rest }}+70 \%\right.$ to $80 \%$ of $\left.\left(\mathrm{HR}_{\text {peak }}-\mathrm{HR}_{\text {rest }}\right)\right]$ in week 12 .

Muscle strength training Resistance exercise of lower and upper extremities was based on the baseline 1-repetition maximum (1-RM). Training intensity started at $30 \%$ of the $1-\mathrm{RM}$ during the first week and was increased until $50 \%$ to $60 \%$ of $1-\mathrm{RM}$ in week 12 .

Group sports Sports, such as badminton, soccer, swimming, and balancing games were performed with the aim being to promote enjoyment of sports and overcome any lack of confidence patients may have felt about exercising.

Cognitive-behavioral intervention This (once a week, two hours per session) was based on a cognitive-behavioral problem-solving protocol for individual cancer patients [24] and a group problem-solving protocol [34]. This problemsolving training showed to have beneficial short- and longterm effects for cancer survivors in quality of life [25]. Furthermore, it has been effectively applied for a variety of mental health problems, such as depression and anxiety, and medical conditions including diabetes, back pain, arthritis, hypertension, headaches, and obesity [10, 23]. During CBT, the participants learned to apply self-management skills [9] in striving for personal goals (e.g., in physical activity, work, household, hobbies, family relationships, and social contacts). Generalization to daily life during and after rehabilitation was promoted by practicing activities during sessions and by homework assignments (maximally $30 \mathrm{~min}$ weekly). The first 3 weeks focused primarily on exchanging participants' experiences with cancer, psycho-education about stress, relaxation, fatigue, exercise physiology, illness perceptions, and on promoting optimism and self-efficacy for self-management. From week 4 onward, participants were primarily trained in applying self-management skills to realize personal goals by practicing the following steps in the circular problemsolving process: (1) problem orientation; (2) problem definition and formulation and goal setting; (3) generation of alternative solutions (brainstorming); (4) decision-making; and (5) solution implementation and verification.

\section{Outcomes}

Socio-demographic and medical data were collected using a self-report questionnaire. Medical data were confirmed by the referring physicians.

Quality of life was assessed by the multidimensional European Organization for Research and Treatment of Cancer Quality of Life Questionnaire C30 (EORTC QLQC30) [1], which assessed cancer-specific quality of life. The EORTC QLQ-C30 is a reliable and valid instrument that has been used in many studies evaluating clinical and psychosocial interventions with cancer patients [1, 3, 19]. The 30-item EORTC QLQ-C30 incorporates a global quality of life scale and five functional scales, namely, physical functioning, social functioning, role functioning, emotional functioning, and cognitive functioning, and three symptom scales, fatigue, pain, and nausea and vomiting. In this study, we report the results of the global scale, the functional scales, and one symptom scale (i.e., fatigue) since these scales are most relevant for participants who 
Fig. 1 Flow of the participants through the study. $P T+C B T$ physical training plus cognitivebehavioral therapy, $P T$ physical training

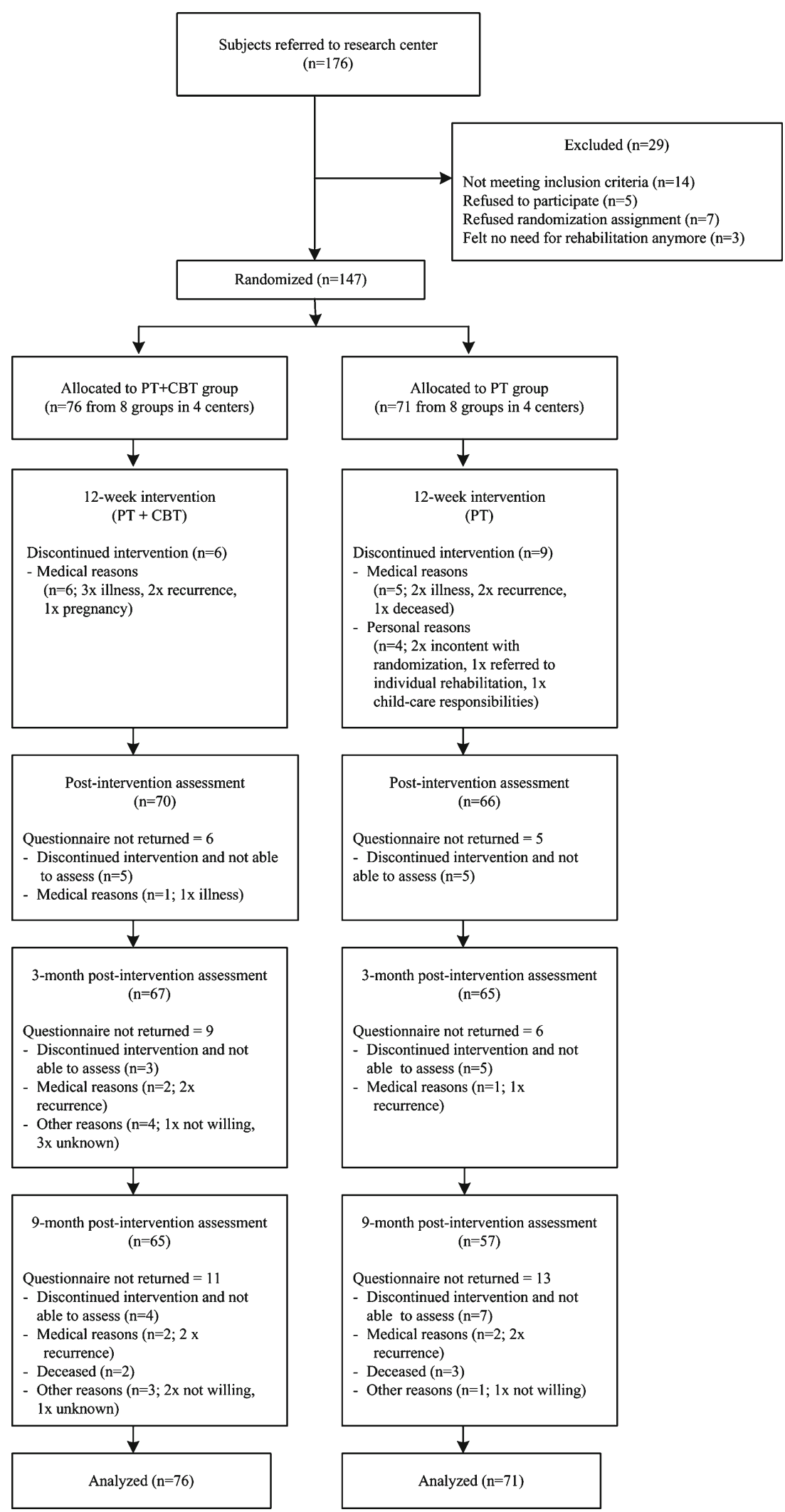


have already completed primary treatment for cancer. After applying a linear transformation procedure according to the EORTC QLQ C-30 manual, the scores of the scales ranged from 0 to 100 . A higher score represents a higher quality of life at the global and functional scales and a higher level of fatigue. The Cronbach's alphas in the present study were high for each of the seven scales $(0.7-0.9)$ at all measurement occasions. Differences of at least ten points were classified as a minimum clinically meaningful change. Changes of less than ten points were regarded as clinically irrelevant, and changes of more than 20 points were classed as large effects [27].

The 12-item Physical Activity Scale for the Elderly (PASE), a valid and reliable questionnaire [31] was used to assess whether the participants maintained being physical active once the program was completed. Questions deal with physical activities, such as leisure, sports, occupational, housework, and gardening. The questionnaire records the frequency of participation in these activities over the preceding 7 days. Scoring procedures were derived from motion sensor counts, physical activity diaries, and a global activity self-assessment. The total PASE score is computed by multiplying the amount of time spent in each activity by the item weights and summing over all activities. The PASE generates a single composite score of physical activity that ranges from 0 to 400 .

\section{Data analysis}

For a comparison between the randomized groups on the primary outcome global quality of life, a sample size of 64 participants in each group was estimated to detect a moderate effect-size $(d=0.50)$ at post-intervention with a power of 0.80 and a two-tailed alpha of 0.05 . Accounting for an estimated dropout of $10 \%, 71$ participants in each group were needed.

The effect of PT + CBT compared to PT on quality of life was tested at post-intervention and 3- and 9-month postintervention according to the intention-to-treat principle. Longitudinal analyses were conducted, using linear mixedeffects models while taking the different levels (training group, participant, and time) into account. The Akaike Information Criterion was used as a measure of fit of the models with a lower value indicating a better fit. To determine whether changes in quality of life were maintained from post-intervention to 9-month post-intervention, statistical testing was performed to examine whether the

Table 1 Baseline characteristics

\begin{tabular}{|c|c|c|c|}
\hline Variable & Overall $(n=147)$ & $\mathrm{PT}+\mathrm{CBT}$ group $(n=76)$ & PT group $(n=71)$ \\
\hline Age (years) & $48.8 \pm 10.9$ & $47.8 \pm 10.5$ & $49.9 \pm 11.3$ \\
\hline \multicolumn{4}{|l|}{ Sex } \\
\hline Female & $123(83.7)$ & $66(86.8)$ & $57(80.3)$ \\
\hline \multicolumn{4}{|l|}{ Educational level } \\
\hline Low & $20(13.6)$ & $6(7.9)$ & $14(19.7)$ \\
\hline Middle & $72(49.0)$ & $40(52.6)$ & $32(45.1)$ \\
\hline High & $55(36.8)$ & $30(39.5)$ & $25(35.2)$ \\
\hline \multicolumn{4}{|l|}{ Marital status } \\
\hline Married/living together & $104(70.7)$ & $53(69.7)$ & $51(71.8)$ \\
\hline Employed at diagnosis & $107(72.8)$ & $54(71.1)$ & $53(74.6)$ \\
\hline Body mass index $\left(\mathrm{kg} \mathrm{m}^{2}\right)$ & $27.5 \pm 6.2$ & $27.4 \pm 6.7$ & $27.7 \pm 5.8$ \\
\hline \multicolumn{4}{|l|}{ Type of cancer } \\
\hline Breast & $82(55.8)$ & $48(63.2)$ & $34(47.9)$ \\
\hline Hematological & $23(16.6)$ & $15(19.7)$ & $8(11.3)$ \\
\hline Gynecological & $17(11.6)$ & $6(7.9)$ & $11(15.5)$ \\
\hline Urogenital & $9(5.5)$ & $3(3.9)$ & $6(8.5)$ \\
\hline Lung & $4(2.7)$ & $2(2.6)$ & $2(2.8)$ \\
\hline Colon & $3(2.0)$ & $1(1.3)$ & $2(2.8)$ \\
\hline Other & $9(6.2)$ & $1(1.3)$ & $8(11.3)$ \\
\hline \multicolumn{4}{|c|}{ Type of treatment (>3 months ago) } \\
\hline Surgery & $126(85.7)$ & $64(84.2)$ & $62(87.3)$ \\
\hline Chemotherapy & $100(68.0)$ & $55(72.4)$ & $45(63.4)$ \\
\hline Radiotherapy & $84(57.1)$ & $43(56.6)$ & $41(57.7)$ \\
\hline Time post-treatment (years) & $1.3 \pm 1.7$ & $1.2 \pm 1.3$ & $1.4 \pm 2.1$ \\
\hline
\end{tabular}

Data are presented as mean \pm standard deviation for continuous variables and frequency (percentage) for categorical variables. $P T+C B T$ physical training plus cognitive-behavioral therapy, $P T$ physical training 
regression coefficients were different. In these analyses, the program accounts for missing data based on the observed data. Statistical analysis was performed using $\mathrm{R}$ software, version 2.5.1. (www.r-project.org). Two-sided significance tests were used $(\alpha<0.05)$.

\section{Results}

Table 1 presents the baseline characteristics of the study participants. The groups were balanced on all sociodemographic and medical variables. Both, PT $+\mathrm{CBT}$ and PT participants completed $83.5 \%$ of 24 physical training sessions (PT $+\mathrm{CBT}, 20 \pm 4.7$; PT, 20 \pm 5.2 ), and $\mathrm{PT}+\mathrm{CBT}$ participants completed $82.4 \%$ of 12 cognitive-behavioral sessions (9.9 \pm 2.4$)$. Of the PT + CBT participants, $92.1 \%$, $88.2 \%$, and $85.5 \%$ completed the assessments at postintervention and 3- and 9-month post-intervention, respec- tively. Of the PT participants, $93.0 \%, 91.5 \%$, and $81.7 \%$ completed the assessments at post-intervention and 3- and 9month post-intervention, respectively (Fig. 1). One participant, assigned to PT, collapsed during the intervention and deceased at the first-aid station. Autopsy showed that death was caused of by a cardiac arrest as result of a hemorrhage from a residual carcinoma in the participants' left primary bronchi. The physicians judged that the death was not related to the exercise. No further adverse events were reported.

Table 2 shows the descriptive study measures over the 1year study period. Multilevel linear mixed-effects models revealed no significant differences in changes from baseline to post-intervention and to 3- and 9-month post-intervention in global quality of life between PT $+\mathrm{CBT}$ and PT (Table 3). The physical, role, emotional, cognitive, and social functioning subscales and the fatigue subscale all demonstrated the same pattern of change. Significant

Table 2 Quality of life (EORTC-QLQ-30) and physical activity (PASE) over the 1-year study period

\begin{tabular}{|c|c|c|c|c|c|c|c|}
\hline & $\begin{array}{l}\text { Baseline } \\
\text { Mean (SD) }\end{array}$ & $\begin{array}{l}\text { Post- } \\
\text { intervention }^{\mathrm{a}} \\
\text { Mean (SD) }\end{array}$ & $\begin{array}{l}\text { Increase of }>10 \\
\text { points }^{b} \mathrm{~N}(\%)\end{array}$ & $\begin{array}{l}\text { 3-month post- } \\
\text { intervention } \\
\text { Mean (SD) }\end{array}$ & $\begin{array}{l}\text { Increase of }>10 \\
\text { points }^{b} \mathrm{~N}(\%)\end{array}$ & $\begin{array}{l}\text { 9-month post- } \\
\text { intervention } \\
\text { Mean (SD) }\end{array}$ & $\begin{array}{l}\text { Increase of }>10 \\
\text { points }^{\mathrm{b}} \mathrm{N}(\%)\end{array}$ \\
\hline \multicolumn{8}{|c|}{ Global quality of life } \\
\hline $\mathrm{PT}$ & $57.7(16.7)$ & $74.1(14.8)$ & $39(59)$ & $71.1(18.7)$ & $33(51)$ & $70.2(18.2)$ & $30(52)$ \\
\hline $\mathrm{PT}+\mathrm{CBT}$ & $56.5(18.4)$ & $71.3(16.4)$ & $39(56)$ & $66.5(20.7)$ & $28(42)$ & $67.9(19.6)$ & $30(46)$ \\
\hline \multicolumn{8}{|c|}{ Physical functioning } \\
\hline PT & $73.9(14.2)$ & $84.1(12.0)$ & $34(52)$ & $83.6(16.3)$ & $33(51)$ & $85.2(14.6)$ & $31(53)$ \\
\hline $\mathrm{PT}+\mathrm{CBT}$ & $71.7(13.3)$ & $85.5(10.5)$ & $46(66)$ & $83.8(13.3)$ & $37(55)$ & $82.5(15.6)$ & $36(55)$ \\
\hline \multicolumn{8}{|c|}{ Role functioning } \\
\hline PT & $59.6(24.2)$ & $74.0(24.3)$ & $37(56)$ & $74.9(23.4)$ & $36(54)$ & $77.0(24.5)$ & $36(62)$ \\
\hline $\mathrm{PT}+\mathrm{CBT}$ & $55.0(24.2)$ & $75.2(20.0)$ & $49(70)$ & $67.4(24.0)$ & $36(55)$ & $70.8(26.2)$ & $37(57)$ \\
\hline \multicolumn{8}{|c|}{ Emotional functioning } \\
\hline PT & $63.6(21.0)$ & $76.0(19.4)$ & $29(44)$ & $76.4(21.0)$ & $28(42)$ & $75.3(23.2)$ & $24(41)$ \\
\hline $\mathrm{PT}+\mathrm{CBT}$ & $60.7(22.1)$ & $75.8(18.9)$ & $37(53)$ & $73.6(19.2)$ & $31(48)$ & $70.6(22.5)$ & $26(40)$ \\
\hline \multicolumn{8}{|c|}{ Cognitive functioning } \\
\hline PT & $66.9(24.6)$ & $76.5(21.9)$ & $32(48)$ & $76.7(21.8)$ & $34(52)$ & $79.0(21.1)$ & $28(48)$ \\
\hline $\mathrm{PT}+\mathrm{CBT}$ & $62.3(27.0)$ & $72.4(21.0)$ & $34(49)$ & $72.9(24.2)$ & $34(51)$ & $73.3(22.6)$ & $32(54)$ \\
\hline \multicolumn{8}{|c|}{ Social functioning } \\
\hline PT & $64.5(26.4)$ & $83.8(20.5)$ & $41(62)$ & $81.8(24.4)$ & $41(63)$ & $82.8(23.3)$ & $34(59)$ \\
\hline $\mathrm{PT}+\mathrm{CBT}$ & $61.4(27.4)$ & $81.2(19.6)$ & $45(64)$ & $75.6(23.3)$ & $41(61)$ & $80.0(24.5)$ & $37(57)$ \\
\hline \multicolumn{8}{|l|}{ Fatigue } \\
\hline $\mathrm{PT}$ & $49.0(22.0)$ & $31.0(18.6)$ & $48(73)$ & $33.3(20.6)$ & $44(68)$ & $35.6(22.7)$ & $37(64)$ \\
\hline $\mathrm{PT}+\mathrm{CBT}$ & $52.8(24.5)$ & $34.8(17.5)$ & $47(67)$ & $37.5(24.1)$ & $44(66)$ & $36.2(25.3)$ & $41(63)$ \\
\hline \multicolumn{8}{|c|}{ Physical activity } \\
\hline PT & $110.0(57.4)$ & $136.8(78.1)$ & - & $118.0(72.3)$ & - & $140.4(87.1)$ & - \\
\hline $\mathrm{PT}+\mathrm{CBT}$ & $116.1(60.5)$ & $140.5(77.5)$ & - & $140.3(81.3)$ & - & $138.9(80.9)$ & - \\
\hline
\end{tabular}

PT: $n=71$ at baseline, $n=66$ at post-intervention, $n=65$ at 3 -month post-intervention and $n=58$ at 9 -month post-intervention; PT + CBT: $n=76$ at baseline, $n=70$ at post-intervention, $n=67$ at 3-month post-intervention and $n=65$ at 9-month post-intervention

EORTC-QLQ-30 European Organization for Research and Treatment of Cancer Quality of Life Questionnaire C30 (range, 0-100), PASE Physical Activity Scale for the Elderly (range, $0-400$ ), $S D$ standard deviation, $N$ number of participants, $P T$ physical training, $P T+C B T$ physical training plus cognitive-behavioral therapy

${ }^{\mathrm{a}}$ The intervention period comprised twelve weeks.

${ }^{b}$ Note that a change of 10 points represents a clinically-important difference. 


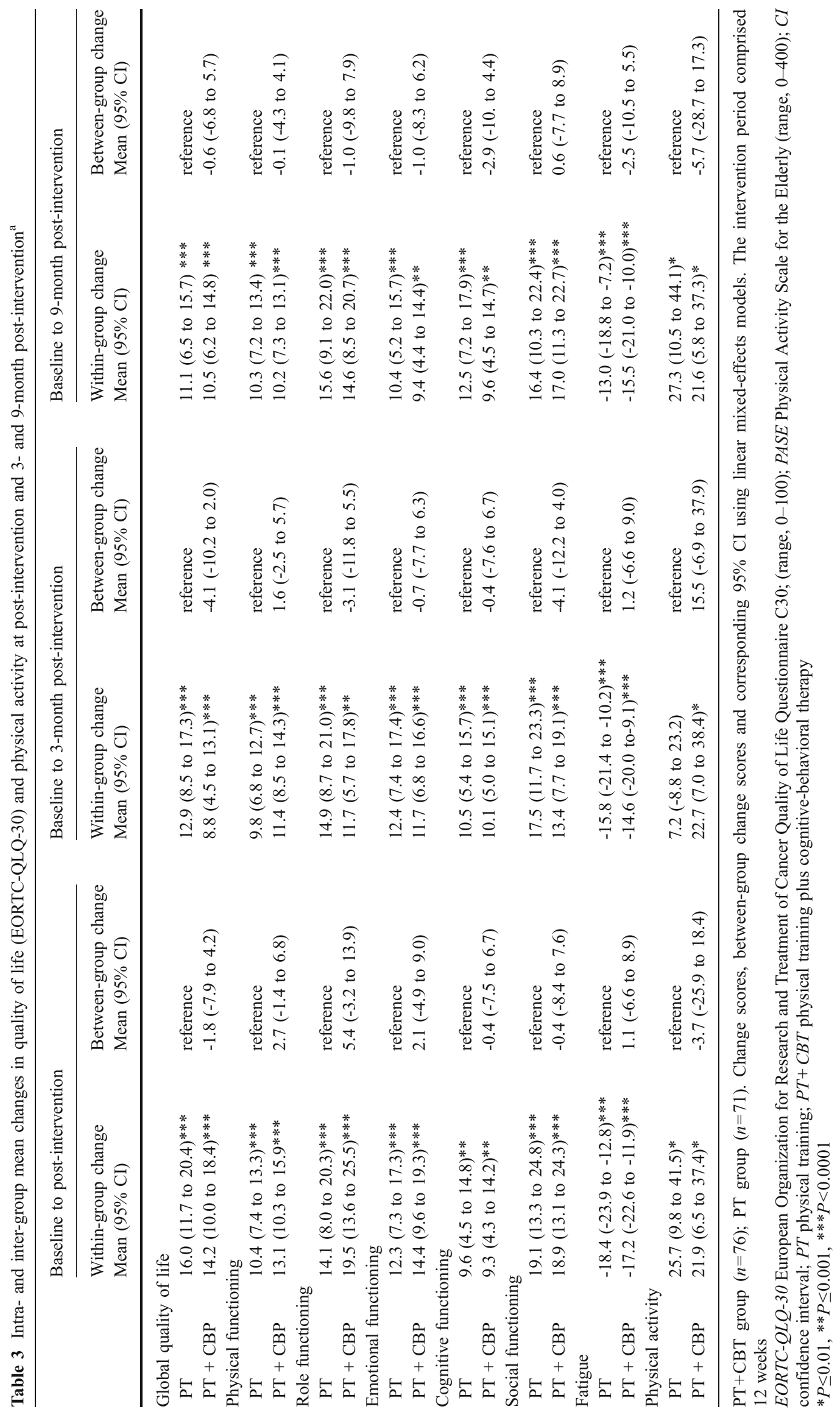


improvements $(p<0.001)$ in global quality of life and in the other domains of quality of life were found in the PT group and in the $\mathrm{PT}+\mathrm{CBT}$ group immediately following the intervention and at 3- and at 9-month post-intervention compared to pre-intervention. Almost all of these improvements were larger than ten points, which is considered to be clinically relevant [27]. In both $\mathrm{PT}$ and $\mathrm{PT}+\mathrm{CBT}$, the shortterm improvements in all domains of quality of life were maintained from post-intervention to 9-month post-intervention except for a statistically significant but not clinically relevant decrease in global quality of life of PT participants $(p=0.04,3.9$-point difference). Figure 2 shows the changes of quality of life, physical functioning, emotional functioning, and role functioning from baseline to 9-month post-intervention by intervention assignment.

Similar to the findings on quality of life, changes in physical activity were not different between $\mathrm{PT}+\mathrm{CBT}$ and PT (Table 3). Significant improvements $(p<0.05)$ in physical activity were found in the PT and in the PT+ CBT groups immediately following the intervention and at 3- and at 9-month post-intervention compared to preintervention, except for PT at 3-month follow-up. At 9month post-intervention, physical activity levels were not different to post-intervention ( $p=0.9$ and $p=0.8$ for $\mathrm{PT}+$ CBT and PT, respectively).

\section{Discussion}

In contrast to our hypothesis, but in line with the short-term effects, no long-term additional positive effect was found on quality of life when our physical training program was complemented with cognitive-behavioral therapy. Our findings are also not consistent with previous reports, suggesting that the effect of cognitive-behavioral therapy may become more prominent over longer follow-up times [2, 25]. An explanation may be that the physical training intervention in the present trial comprised a self-management approach. It has been shown that including social-cognitive components, such as self-management, in an intervention may have positive effects on quality of life in cancer patients [12]. Furthermore, PT was offered in a group format that provides opportunities for social interaction, social comparison, and group support that might improve self-efficacy and subsequently quality of life [12]. Possible differential effects between physical training and cognitive-behavioral therapy might be diminished by integrating social-cognitive components into the physical training in a standardized way.

Recent reviews and meta-analyses showed that physical training has beneficial short-term effects on cancer survivors' quality of life [20,30]. However, evidence for the durability of these beneficial effects is limited [20]. Our
Fig. 2 Mean changes of quality of life, physical functioning, emotional functioning, and role functioning measured using the European Organization for Research and Treatment of Cancer Quality of Life Questionnaire C30 from baseline to 9-month post-intervention by intervention assignment. Changes are based on linear mixed-effects models. The dashed line represents the minimally clinically important difference. $P T$ physical training, $P T+C B T$ physical plus cognitive-behavioral therapy
Global quality of life

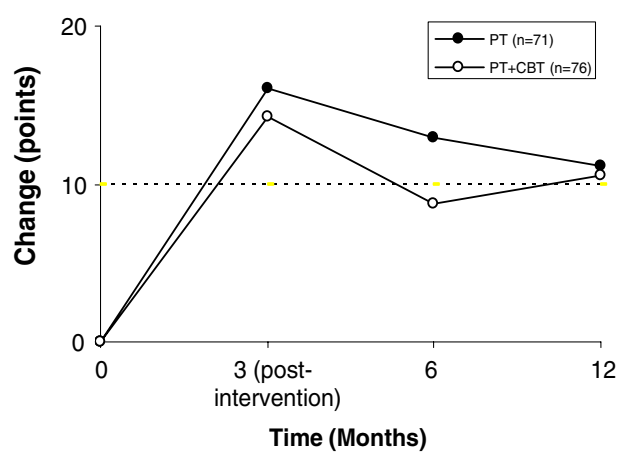

Emotional functioning

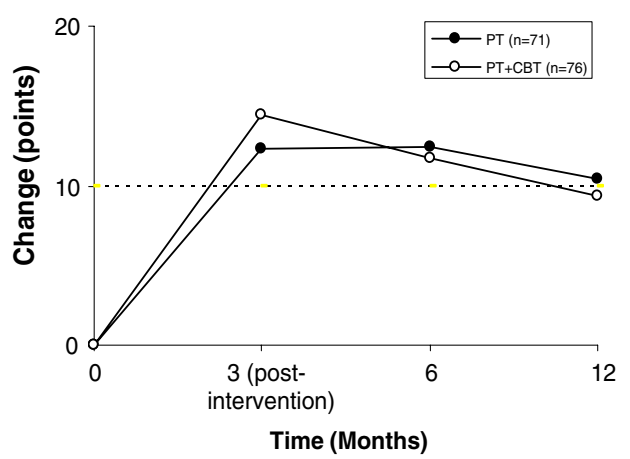

Physical functioning

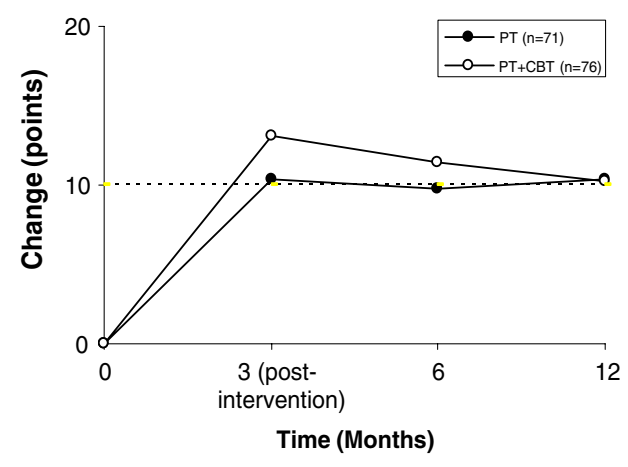

Role functioning

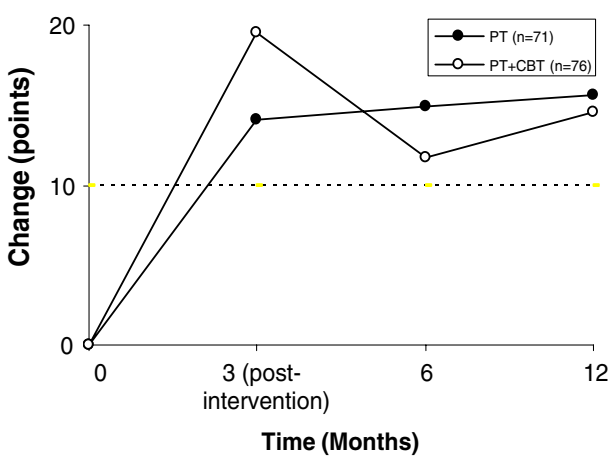


results indicate that the positive short-term effects of physical training on quality of life were maintained at follow-up. Quality of life of the cancer survivors participating in our study was improved following 12-week self-management physical training consisting of aerobic training, resistance exercise, and group sports. Nine months after the intervention, improvements in global quality of life, physical, role, emotional, cognitive, and social functioning and fatigue were sustained and remained clinically relevant. Only participants in the PT group reported a decrease in global quality of life from post-intervention to 9month post-intervention. However, this small decrease was not clinically relevant, and the improvement in global quality of life at 9-month post-intervention was still clinically relevant compared to pre-intervention. Global quality of life at 9-month post-intervention of PT participants was comparable to that of $\mathrm{PT}+\mathrm{CBT}$ participants. Moreover, the participants maintained their physical activity levels once the program was completed.

Three other studies $[4,11,22]$ reported long-term results following an exercise intervention for cancer patients who had completed their cancer-related treatment. Similar to our findings in a mixed group of cancer survivors, Milne et al. [22] showed that quality of life of breast cancer survivors was improved directly after and 3 months following a 12week combined aerobic and resistance exercise intervention. Contrary to the findings in the present trial, they reported that quality of life still increased from post-intervention to 3month post-intervention. This effect may be partly due to the attention given to the participants during regularly telephone calls (every 3 weeks) during follow-up, whereas we did not approach our participants during follow-up. Daley et al. [11] showed a beneficial effect on breast cancer survivors' quality of life directly following an 8-week physical training program when compared to control. Results were not maintained at 4-month follow-up. To date, only one study included a 1-year follow-up [4]. Their 7-week group rehabilitation program, however, did not lead to improvements in quality of life on the short- and the long-term. This could well reflect the short duration of the intervention and the low intensity of the program, which included only four information sessions, three coping skills training sessions, and four light-intensity physical training sessions.

To appreciate the findings, some aspects of the study need to be addressed. Strengths of the present study were the length of follow-up, the use of intention-to treat analyses, the supervised, standardized intervention, the large sample size, high attendance rates, and low drop-out rates. A limitation of the study was the lack of a control group for the long-term effects. We included a waiting-list comparison group for the evaluation of the effects immediately after our intervention and showed significant improvements in quality of life in the intervention condition compared to control [16, 17]. However, for feasibility reasons, due to the fact that cancer survivors were highly motivated to attend an exercise intervention [32] and that alternatives were available in The Netherlands, a control group could not be assessed at 3- and 9-month postintervention. Therefore, we cannot definitely conclude that the improvements in quality of life at the end of the followup period are specific to our intervention. Nonetheless, considering that quality of life was significantly and clinically relevantly improved directly following the intervention compared to waiting-list control patients and that these improvements were maintained at 9-month postintervention, it seems plausible that the beneficial longterm effects are not simply attributable to the passage of time and may likely be a consequence of the intervention.

The changes of quality of life in PT $+\mathrm{CBT}$ and PT were of a similar magnitude. It is unlikely that including more subjects in the study would have changed the conclusion that cognitive-behavioral therapy did not add to the beneficial effects of physical training. This is illustrated by a post-hoc power analysis using the change scores found in the present study: More than 1,100 participants per group would have been required to show statistically significant differences in improvement of quality of life between $\mathrm{PT}+\mathrm{CBT}$ and PT. It is doubtful whether a significant difference in this study would have sufficient clinical relevance. The fact that adding cognitive-behavioral therapy did not have additional effects does not allow the conclusion that cognitive-behavioral therapy by itself may not improve quality of life in cancer survivors, as we did not include a group who received cognitive-behavioral therapy alone in our design.

Participants in the trial were well motivated to participate in the intervention and applied for participation on their own initiative. In addition, their attendance rates remained high during the intervention. Their quality of life appeared to be low at baseline. The results can be generalized to cancer survivors with physical and/or psychosocial problems who voluntarily apply for a physical training program.

In conclusion, the short- and long-term quality of life of cancer survivors improved following participation in a physical training program. Adding cognitive-behavioral therapy to this supervised group-based self-management physical training appears not to further enhance the beneficial effects of physical training alone. Physical training should be considered as a useful component in the standard care for cancer survivors. Physicians should encourage participation in physical exercise programs.

Acknowledgments We would like to acknowledge the contribution to our study of Prof. R.W. Trijsburg (Erasmus Medical Center Rotterdam) who passed away on April 8, 2007. Furthermore, we thank the professional staff and all participants in all study centers. This study was supported by grants from the Dutch Cancer Society 
(UU-2000-2585) Maastricht University (Caphri) and the Comprehensive Cancer Centre North-East. The funders were independent from the conduct and outcomes of this study.

Conflicts of interest None declared.

\section{References}

1. Aaronson NK, Ahmedzai S, Bergman B, Bullinger M, Cull A, Duez NJ et al (1993) The European Organization for Research and Treatment of Cancer QLQ-C30: a quality-of-life instrument for use in international clinical trials in oncology. J Natl Cancer Inst 85:365-376 doi:10.1093/jnci/85.5.365

2. Antoni MH, Lechner SC, Kazi A, Wimberly SR, Sifre T, Urcuyo KR et al (2006) How stress management improves quality of life after treatment for breast cancer. J Consult Clin Psychol 74:11431152

3. Apolone G, Filiberti A, Cifani S, Ruggiata R, Mosconi P (1998) Evaluation of the EORTC QLQ-C30 questionnaire: a comparison with SF-36 Health Survey in a cohort of Italian long-survival cancer patients. Ann Oncol 9:549-557 doi:10.1023/A:1008264412398

4. Berglund G, Bolund C, Gustafsson UL, Sjoden PO (1994) Oneyear follow-up of the 'Starting Again' group rehabilitation programme for cancer patients. Eur J Cancer 30A:1744-1751 doi:10.1016/0959-8049(94)00330-8

5. Bjordal K, Mastekaasa A, Kaasa S (1995) Self-reported satisfaction with life and physical health in long-term cancer survivors and a matched control group. Eur $\mathrm{J}$ Cancer B Oral Oncol 31B:340-345 doi:10.1016/0964-1955(95)00039-9

6. Borg GA (1982) Psychophysical bases of perceived exertion. Med Sci Sports Exerc 14:377-381

7. Courneya KS, Friedenreich CM, Sela RA, Quinney HA, Rhodes RE, Handman M (2003) The group psychotherapy and homebased physical exercise (group-hope) trial in cancer survivors: Physical fitness and quality of life outcomes. Psychooncology 12:357-374 doi:10.1002/pon.658

8. Courneya KS, Mackey JR, Bell GJ, Jones LW, Field CJ, Fairey AS (2003) Randomized controlled trial of exercise training in postmenopausal breast cancer survivors: cardiopulmonary and quality of life outcomes. J Clin Oncol 21:1660-1668 doi:10.1200/ JCO.2003.04.093

9. Creer TL (2002) Self-management of chronic illness. Handbook of self regulation. Academic, San Diego, CA, US

10. D'Zurilla TJ, Nezu AM (2007) Problem-solving therapy: a positive approach to clinical intervention, 3rd edn. Springer, New York

11. Daley AJ, Crank H, Saxton JM, Mutrie N, Coleman R, Roalfe A (2007) Randomized trial of exercise therapy in women treated for breast cancer. J Clin Oncol 25:1713-1721 doi:10.1200/ JCO.2006.09.5083

12. Graves KD (2003) Social cognitive theory and cancer patients' quality of life: a meta-analysis of psychosocial intervention components. Health Psychol 22:210-219 doi:10.1037/0278-6133.22.2.210

13. Helgeson VS, Cohen S, Schulz R, Yasko J (2001) Long-term effects of educational and peer discussion group interventions on adjustment to breast cancer. Health Psychol 20:387-392 doi:10.1037/0278-6133.20.5.387

14. Karvinen KH, Courneya KS, North S, Venner P (2007) Associations between exercise and quality of life in bladder cancer survivors: a population-based study. Cancer Epidemiol Biomarkers Prev 16:984-990 doi:10.1158/1055-9965.EPI-06-0680
15. Karvonen J, Vuorimaa T (1988) Heart rate and exercise intensity during sports activities. Practical application. Sports Med 5:303311 doi:10.2165/00007256-198805050-00002

16. Korstjens I, May AM, van Weert E, Mesters I, Tan F, Ros WJG et al (2008) Quality of life after cancer rehabilitation: a randomized controlled trial comparing physical training with a multidisciplinary physical and cognitive-behavioral training. Psychosom Med 70:422-429 doi:10.1097/PSY.0b013e31816e038f

17. Korstjens I, May AM, van Weert E, Mesters I, van den Borne B (2006) Quality of life after multidisciplinary cancer rehabilitation, combining physical training and psycho-education. Psychooncology $15: \mathrm{S} 293$

18. May AM, van Weert E, Korstjens I, Hoekstra-Weebers JE, Van Der Schans CP, Zonderland ML et al (2008) Improved physical fitness of cancer survivors: A randomised controlled trial comparing physical training with physical and cognitive-behavioural training. Acta Oncol 47:825-834 doi:10.1080/02841860701666063

19. McLachlan SA, Devins GM, Goodwin PJ (1998) Validation of the European Organization for Research and Treatment of Cancer Quality of Life Questionnaire (QLQ-C30) as a measure of psychosocial function in breast cancer patients. Eur J Cancer 34:510-517 doi:10.1016/S0959-8049(97)10076-4

20. McNeely ML, Campbell KL, Rowe BH, Klassen TP, Mackey JR, Courneya KS (2006) Effects of exercise on breast cancer patients and survivors: a systematic review and meta-analysis. Can Med Assoc J 175:34-41 doi:10.1503/cmaj.051073

21. Michael YL, Kawachi I, Berkman LF, Holmes MD, Colditz GA (2000) The persistent impact of breast carcinoma on functional health status: prospective evidence from the Nurses' Health Study. Cancer 89:2176-2186 doi:10.1002/1097-0142(20001201) 89:11<2176::AID-CNCR5>3.0.CO;2-6

22. Milne HM, Wallman KE, Gordon S, Courneya KS (2008) Effects of a combined aerobic and resistance exercise program in breast cancer survivors: a randomized controlled trial. Breast Cancer Res Treat 108:279-288 doi:10.1007/s10549-007-9602-Z

23. Nezu AM (2004) Problem-solving and behavioor therapy revisited. Behav Ther 35:1-33 doi:10.1016/S0005-7894(04)80002-9

24. Nezu AM, Nezu CM, Houts PS, Friedman SH, Faddis S (1998) Helping cancer patients cope: a problem-solving approach. American Psychological Association, Washington, DC, USA

25. Nezu AM, Nezu CM, Felgoise SH, McClure KS, Houts PS (2003) Project Genesis: assessing the efficacy of problem-solving therapy for distressed adult cancer patients. J Consult Clin Psychol 71:1036-1048 doi:10.1037/0022-006X.71.6.1036

26. Osborn RL, Demoncada AC, Feuerstein M (2006) Psychosocial interventions for depression, anxiety, and quality of life in cancer survivors: meta-analyses. Int J Psychiatry Med 36:13-34 doi:10.2190/EUFN-RV1K-Y3TR-FK0L

27. Osoba D, Rodrigues G, Myles J, Zee B, Pater J (1998) Interpreting the significance of changes in health-related qualityof-life scores. J Clin Oncol 16:139-144

28. Pennebaker JW, Beall SK (1986) Confronting a traumatic event: toward an understanding of inhibition and disease. J Abnorm Psychol 95:274-281 doi:10.1037/0021-843X.95.3.274

29. Scheier MF, Helgeson VS, Schulz R, Colvin S, Berga S, Bridges MW et al (2005) Interventions to enhance physical and psychological functioning among younger women who are ending nonhormonal adjuvant treatment for early-stage breast cancer. J Clin Oncol 23:4298-4311 doi:10.1200/JCO.2005. 05.362

30. Schmitz KH, Holtzman J, Courneya KS, Masse LC, Duval S, Kane R (2005) Controlled physical activity trials in cancer survivors: a systematic review and meta-analysis. Cancer Epidemiol Biomarkers Prev 14:1588-1595 doi:10.1158/1055-9965.EPI04-0703

31. Schuit AJ, Schouten EG, Westerterp KR, Saris WH (1997) Validity of the Physical Activity Scale for the Elderly (PASE): 
according to energy expenditure assessed by the doubly labeled water method. J Clin Epidemiol 50:541-546 doi:10.1016/S08954356(97)00010-3

32. Stull VB, Snyder DC, Demark-Wahnefried W (2007) Lifestyle interventions in cancer survivors: designing programs that meet the needs of this vulnerable and growing population. J Nutr 137:243S-248S

33. Sweeney C, Schmitz KH, Lazovich D, Virning BA, Wallace RB, Folsom AR (2006) Functional limitations in elderly female cancer survivors. J Natl Cancer Inst 98:521-529
34. van den Hout JH, Vlaeyen JW, Heuts PH, Zijlema JH, Wijnen JA (2003) Secondary prevention of work-related disability in nonspecific low back pain: does problem-solving therapy help? A randomized clinical trial. Clin J Pain 19:87-96 doi:10.1097/ 00002508-200303000-00003

35. van Weert E, Hoekstra-Weebers JE, May AM, Korstjens I, Ros WJ, Van Der Schans CP (2008) The development of an evidencebased physical self-management rehabilitation programme for cancer survivors. Patient Educ Couns 71:169-190 doi:10.1016/j. pec.2007.11.027 